\title{
PRINCESINHA DO NORTE POR BABETTE: IDENTIDADES E HOMOSSOCIABILIDADES EM COLATINA NOS ANOS 60
}

\section{LITTLE PRINCESS OF NORTH BY BABETTE: IDENTITIES AND HOMOSOCIALITIES IN COLATINA IN THE 60s}

\author{
Randas Gabriel Aguiar Freitas ${ }^{1}$ \\ Luiz Cláudio Moisés Ribeiro ${ }^{2}$ \\ Carlos Eugênio Soares de Lemos ${ }^{3}$
}

\begin{abstract}
RESUMO
Neste artigo discutiremos as classificações identitárias e as formas de sociabilidade das dissidências de gênero e sexualidade na cidade de Colatina no Espírito Santo durante os anos 1960. O pano de fundo teórico está na abordagem foucaultiana acerca da sexualidade. Interpelamos as questões de identidade a partir dos estudos culturais dialogando com os estudos queer, o que nos permite discorrer sobre identidades ao fugir da rigidez categórica e apresentar a plasticidade do processo de construção do eu e do outro. Buscamos verificar os espaços de sociabilidades desses sujeitos em uma cidade interiorana e os diálogos possíveis com outras cidades. A fonte que possibilitou essa pesquisa provém da coluna Colatina em Hi-Fi, escrita por Babette entre 1965 e 1968 no jornal O Snob, publicado na cidade do Rio de Janeiro (RJ).
\end{abstract}

Palavras-chaves: Homossociabilidades. Colatina. Identidades. Gênero. Sexualidades.

\begin{abstract}
This article discuss gender and sexuality dissents on the countryside of Espirito Santo, the city of Colatina in the 1960's. The theoretical background is placed on Foucault's approach about sexuality. In addition, identities' inquiries are examined according to the cultural studies' persperctive, through the dialogue with queer studies, which allows the discussion on identities avoiding the categorical tightness and presenting the plasticity in the process of construct the self and the other. Through travels between the small town and other cities, and the possible disscussions that may have risen due to this
\end{abstract}

\footnotetext{
${ }^{1}$ Mestrando em História Social das Relações Políticas na Universidade Federal do Espírito Santo. Licenciado em História pela mesma instituição (2017). Bolsista da Fundação de Amparo à Pesquisa do Espírito Santo (Fapes). email: randas.aguiar@live.com

${ }^{2}$ Atualmente é Professor Associado IV do Departamento de História do Centro de Ciências Humanas e Naturais da Universidade Federal do Espírito Santo (CCHN/UFES). Professor do Programa de Pós-Graduação em História (CCHN/UFES), professor do Programa de Pós-Graduação em História da Universidade Estadual de Santa Cruz (Ilhéus/BA). Doutor em História pela Universidade Federal Fluminense. e-mail: sombradoscamaras@gmail.com

${ }^{3}$ Atualmente é Professor Associado I do Departamento de Ciências Sociais da PUCG/UFF. Doutor em Ciências Humanas (Sociologia) pelo IFCS/UFRJ. e-mail: eugeniodelemos@hotmail.com
} 


\section{Revista \\ Debates Insubmissos}

exchange, we persue to verify the sociability of those subjects. The research was possible thanks to Babette's column, Colatina em Hi-Fi, published between 1965 and 1968 on Rio de Janeiro's newspaper called O Snob.

Keywords: homosocialities. Colatina. Identities. Gender. Sexualities.

\section{INTRODUÇÃO}

Uma das maiores dificuldades em historicizar dissidências de gênero e sexualidade em contextos interioranos ou rurais está na ausência de registros dessas experiências, dado que por muito tempo a sexualidade foi reservada ao âmbito privado das relações, e por muitas vezes ainda é forçada a permanecer nessa esfera. Ao historiador cabe optar pela história oral como forma de acessar as narrativas dessas vivências. Felizmente, durante os anos de 1965 e 1968 , um colatinense relatou em sua coluna no jornal doméstico $O S n o b^{4}$, a vida de bonecas e bofes da cidade de Colatina. Os relatos presentes nessa fonte possibilitam que busquemos inferir sobre as experiências desses sujeitos.

A conjuntura dos anos 1960 em Colatina foi marcada pela transformação urbana. Localizada no noroeste do estado do Espirito Santo, Colatina é atravessada pelo Rio Doce. Essa localização propiciou que a cidade se tornasse, em 1949, a maior produtora de café no estado, o que resultou em um crescimento demográfico no interior e no centro urbano. Na década 1950, o município contava com cerca de 100 mil habitantes urbanos e rurais, passando a ter aproximadamente 155 mil nos anos 1960. A população urbana aumentou de 9 mil para 35 mil pessoas. Nesse mesmo período o município atravessava um processo de fragmentação devido à emancipação de regiões dentro do seu território, dando origem a novas cidades. Com a crise do café em 1960 os moradores da zona rural migraram para o centro urbano de Colatina, o que provocou a emergência de indústrias voltadas para agronegócio e a modernização dos bairros às margens do Rio Doce. $\mathrm{O}$ surgimento de agroindústrias foi possível pois a cidade contava com a malha ferroviária Vitória-Minas cortando seu território, e as áreas que eram destinadas ao plantio de café foram utilizadas para pecuária extensiva (ALBANI, 2012).

\footnotetext{
${ }^{4}$ Os exemplares do jornal estão disponíveis no Arquivo Edgard Leuenroth (AEL) da Universidade de Estadual de Campinas (Unicamp).
} 


\section{Revista \\ Debates Insubmissos}

Sob essa conjuntura social e econômica dos anos 60 , emerge uma sociabilização de homossexuais no centro urbano de Colatina. Registrada nas páginas do jornal doméstico $O$ Snob, a coluna Colatina em $\mathrm{Hi}-\mathrm{Fi}$ foi escrita por Babette. O jornal foi idealizado pelo carioca Agildo Guimaraes (Gilka), com o objetivo de tratar da temática "homossexual"5. Produzido no Rio de Janeiro, $O$ Snob circulou de 1963 a 1969 e foi enviado para outros municípios e estados do Brasil que compunham a sua rede ${ }^{6}$. Como aponta Rogério Costa os colunistas se "batizavam" e assinavam suas colunas com nomes femininos. Normalmente os que optavam pelo pseudônimo feminino se identificavam como bicha/boneca (2010, p. 57).

O Snob contava com diversas colunas "assinadas ou não, envolvendo fofocas, pontos de encontros, divulgação e comentários de festas e concursos, além de tornar público os encontros amorosos" (COSTA, 2010, p. 9). A coluna de Babette foi recorrente de janeiro de 1965 a janeiro de 1968, totalizando 18 das 103 edições do jornal. Inicialmente a coluna seria escrita por Maísa, porém, por conta de problemas pessoais ela passou a responsabilidade para Babette $^{7}$. Não sabemos ao certo sobre a pessoa de Babette e seus rumos posteriores à publicação, dado que seu último escrito na coluna finaliza prometendo mais edições, entretanto, dentro do acervo do jornal não foram encontradas mais publicações do Colatina em $\mathrm{Hi}-\mathrm{Fi}^{8}$ a partir de janeiro de 1968.

No conteúdo da coluna identificamos abordagem sobre concursos de misses municipais, estaduais e nacional, como também fofocas e comentários sobre Colatina, Vitória e outras cidades e estados que compõem a rede d'O Snob. Nos mexericos locais são abordados pontos

\footnotetext{
${ }^{5}$ Aqui o termo homossexual está sendo empregado de forma ampla, sem recorte de práticas sexuais, expressões de gênero e identidades sexuais, pois Rogério da Costa (2010) aponta que esse termo era usado dentro da rede $O$ Snob para designar homens que tinham práticas sexuais passivas com outros homens.

${ }^{6}$ Segundo Rogério da Costa (2010, p. 5) a rede do jornal começou a se formar durante os anos 1950, com a participação de diversos grupos (ou turmas) da cidade do Rio de Janeiro e posteriormente passou a contar com a partição de grupos e turmas de outras cidades e estados do Brasil.

${ }^{7}$ Optamos por utilizar os respectivos artigos e pseudônimos empregados pela colunista junto às identidades sexuais e expressões de gênero colocadas, com as devidas problematizações.

${ }^{8} \mathrm{Na}$ edição de janeiro de 1968 a coluna recebe o título de Colatina em Foco, entretanto nem Colatina em Hi-Fi como Colatina em Foco, ou outra coluna assinada por Babette apareceram nas edições posteriores d' $O$ Snob.
} 
de encontros, festividades, espaços de pegação ${ }^{9}$, problemas pessoais, violência e fobias dentro do território da Princesinha do Norte ${ }^{10}$. Ao longo deste artigo, primeiro apresentamos os pressupostos teóricos e históricos acerca das identidades sexuais e as expressões de gênero no Brasil. Em um segundo tópico abordamos as identidades, expressões e noções de gênero e sexualidade nos escritos de Babette. Posteriormente, tratamos dos locais de sociabilidades na cidade e como esses espaços permitiam maiores liberdades ao mesmo tempo evidenciavam como esses sujeitos eram colocados à margem da sociedade. Por fim, num quarto tópico, tecemos algumas considerações acerca de migrações e intercâmbios com outras cidades e estados, que possibilitaram diálogos, articulações e resistências.

\section{CONTEXTUALIZAÇÃO TEÓRICA E HISTÓRICA}

São mencionados pelo menos 9 termos para designar identidades sexuais e de gênero na cidade de Colatina. Cada expressão possui um núcleo próprio de referência que pode ser sexualidade, papéis de gênero, expressões de gênero ou práticas sexuais, podendo ser aplicados como identidade, grupo, estado, qualidade ou local. Em ordem decrescente de quantidade de citações temos os termos: boneca (177), bofe (54), mulher (15), travesti (15), entendido (8), bicha (4), homem (3), gay (2) e homossexualismo (2). Essa informação quantitativa acercas das identidades sexuais e de gênero citadas na coluna não faz sentido sem serem contextualizada com os debates externos (na sociedade brasileira) e internos (dentro da rede $O S n o b$ ).

Cada uma dessas palavras, entendidas como signos, possui núcleos diferentes de elaboração, aplicabilidade e representação de algo ou alguém. Tal representação do outro faz parte do processo de construção da identidade e, por conseguinte, da diferença. Para Tomaz Tadeu da Silva (2005) tanto a identidade quanto a diferença são mutualmente determinadas, sendo elas resultado de atos de criação linguística, ou seja, algo fabricado pelo mundo cultural

\footnotetext{
${ }^{9}$ Pegação pode ser entendida neste trabalho como atos de relacionamento afetivo-sexual em determinados espaços que possibilitavam beijos, caricias e/ou sexo.

${ }^{10}$ Babette se refere a cidade de Colatina de várias formas: Princesinha do Norte sendo a mais recorrente, seguida de Terra do Café e Terra do Sol.
} 


\section{Revista \\ Debates Insubmissos}

e social Na mesma linha de pensamento, Kathryn Woodward (2005) salienta que a linguagem, então, é como um sistema de significação que possui a diferença como método, construindo sentidos às identidades e às diferenças. Tomaz Tadeu da Silva (2005) também evoca que a linguagem é um sistema instável, dado que a identidade de algo se estabelece sob algum signo. Tal signo não consegue contemplar todas as possibilidades de estar de uma identidade. Para o autor, sobre a identidade atua um processo de produção simbólica e discursiva, que está passível dentro da experiência social a vetores de força e relações de poder. Essa possibilidade de definir algo, ou seja, afirmar uma identidade e produzir uma diferença, pode garantir privilégios dentro de uma sociedade. Kathryn Woodward (2005) chama atenção de que a construção da identidade é tanto simbólica quanto social, sendo assim, se um grupo é rotulado simbolicamente como diferente, isso produz consequências reais como exclusão, estigma e desvantagens materiais.

Dentro desse movimento de produção do eu e do outro, temos a construção históricodiscursiva das categorias homem e mulher como polos opostos e divergentes. Sob uma diferenciação por sexo e gênero essas categorias foram objetos dos discursos binários classificatórios. Pelo menos nos últimos dois milênios, a tríade filosofia-religião-ciência atribuiu aos homens as características razão, dominador, forte, público, penetrador, enquanto a mulher foi elaborada sob perspectivas opostas, tendo como atributos a emoção, submissão, fraqueza, privado e penetrada. Essas noções discursivas moldaram a construção dos saberes da sociedade e as experiências sociais desses sujeitos. Como já elencado, as identidades são construídas sob signos, mas essas identidades não dão conta de explicar as experiências sociais dos sujeitos. No dizer de Judith Butler, a pseudo naturalidade em ser mulher e ser homem foi "constituída mediante atos performativos discursivamente compelidos, que produzem o corpo no interior das categorias de sexo e por meio delas" (2003, p. 8). Butler (2003) salienta que

atos, gestos e desejo produzem o efeito de um núcleo ou substância interna, mas o produzem na superfície do corpo, por meio do jogo de ausências significantes, que sugerem, mas nunca revelam, o princípio organizador da identidade como causa. Esses atos, gestos e atuações, entendidos em termos gerais, são performativos, no sentido de que a essência ou identidade que por outro lado pretendem expressar são fabricações manufaturadas e sustentadas por signos corpóreos e outros meios discursivos (BUTLER, 2003, p. 194). 


\section{Revista \\ Debates Insubmissos}

Contradizendo uma noção que busca uma "essência" no gênero, Judith Butler (2003) compreende que o gênero é inscrito no corpo, sendo que os vários atos de gênero produzem uma ideia de gênero, ou seja, pintam o corpo que é uma tela em branco.

No século XVIII teve início uma ordem discursiva que buscava disciplinar a sexualidade. Michel Foucault (1988) afirma que houve um boom na produção de discursos que tratavam sobre o sexo. Para Foucault (1988), o sexo havia se tornado objeto de verdade, e os saberes científicos envoltos de uma moral estavam interessados nas aberrações, perversões e extravagâncias acerca do sexo e, por conseguinte, na correção dessas "falhas". Foucault (1988) cunha essas tecnologias de disciplinamento, regulamentação e normatização como um dispositivo de sexualidade. Nesse movimento ${ }^{11}$ a psiquiatria, a jurisprudência e a literatura transcrevem a homossexualidade como o outro, e dentro desse sistema ela adquire características negativas como perversidade, anomalia, doença e imoralidade. Michel Foucault (1988) destaca que houve um movimento centrifugo em relação a monogamia heterossexual, que atribuiu a diversas outras formas de relacionamentos afetivo-sexuais o caráter patológico, passível de cura. Os discursos dos saberes médico-legal - envoltos de uma perspectiva heteronormativa - patologizaram as relações afetivo-sexuais entre pessoas do mesmo sexo e as expressões de gênero que não se enquadravam na perspectiva binária homem-mulher heterossexual criando, assim, a doença homossexualismo. Foucault (1988) também destaca que essa categorização

possibilitou a constituição de um discurso "de reação": a homossexualidade pôs-se a falar por si mesma, a reivindicar sua legitimidade ou sua "naturalidade" e muitas vezes dentro do vocabulário e com as categorias pelas quais era desqualificada do ponto de vista médico (FOUCAULT, 1988, p. 95).

A afirmação de Michel Foucault torna-se evidente no estudo de James Green (2000) acerca das homossexualidades masculinas no Brasil do século XX. Green (2000) destaca que em meados dos anos 1930 existia uma polaridade de duas identidades entre sujeitos homossexuais e elas eram baseadas nos papéis de gênero esperados para o homem e para a mulher, originando assim, para o gênero masculino, as categorias bichas efeminadas e os

\footnotetext{
${ }^{11}$ Foucault também destaca a histerização do corpo da mulher, a pedagogização do sexo da criança e a socialização das condutas de procriação como elementos desse dispositivo de sexualidade. Ver: FOUCAULT, Michel. História da sexualidade I: a vontade de saber. Rio de janeiro: Graal, 1988.
} 


\section{Revista \\ Debates Insubmissos}

homens "verdadeiros". Essas duas designações consumiam do discurso normativo acerca dos papéis esperados que cada gênero desempenhasse, sendo a bicha efeminada moldada sobre a ideia de mulher (penetrada, submissa) e o homem "verdadeiro" estava dentro do próprio molde de homem (penetrador, dominador).

Dentro da rede $O$ Snob a noção de homem "verdadeiro" foi substituída pela nomenclatura bofe, e o termo bicha por boneca. Para Green (2000), tal entendimento se baseava nas normas rígidas dos papéis de gênero, então, pela perspectiva da $b i c h a$, o bofe não perdia o status social de homem, dado que ele mantinha o papel sexual atribuído ao homem "verdadeiro". Não apenas no ato sexual essa polaridade era representada, como também nas próprias representações sociais sobre si, nas quais o homem "verdadeiro" deveria usar roupas e se comportar nos moldes de uma masculinidade que era esperada para um homem heterossexual, quanto as bichas efeminadas teriam que performar feminilidades.

Esse tipo de enquadramento baseado na construção discursiva acerca das polaridades homem e mulher também afetou as identidades homossexuais femininas. Nádia Nogueira (2005) sublinha que o discurso médico-legal procurou dividir os relacionamentos entre duas mulheres de forma hierárquica, dividindo-as entre as mais e as menos lésbicas. Nessa díade, a menos lésbica era a que tinha relações com outras mulheres, mas performava feminilidade; e a mais lésbica era a que tinha aparência física, pensamentos, ações e sentimentos masculinos. As concepções de masculino e feminino no discurso médico-legal estão alicerceadas nas expectativas de gênero construídas historicamente para homens e mulheres. Nesses moldes discursivos as nomenclaturas foram as mais diversas, sendo invertida uma categoria mais geral que não se baseava nas expressões de gênero ou práticas sexuais da pessoa, normalmente usada de forma pejorativa por representantes do saber médico-legal. Dentro do modelo masculino e feminino, as mulheres que se relacionavam afetivamente e sexualmente com outras mulheres foram "divididas grosseiramente em fanchonas, sapatões - entre vários outros adjetivos, considerada a masculina, a que tem uma postura ativa durante o ato sexual; e a lady, sapatilha, a que supostamente tem uma performance feminina, passiva no ato sexual" (NOGUEIRA, 2005, p. 83). O termo sapatão posteriormente foi reivindicado por lésbicas e ressignificado tirando o tom pejorativo e a atribuição de papel sexual e expressão de gênero masculinos. 


\section{Revista \\ Debates Insubmissos}

Nos anos 1960 também houve transformações sociais e discursivas acerca das práticas de inversão de gênero (travestis, drag queens e crossdressers). Como aponta o estudo de Elias Veras (2020), a prática de travestir-se no carnaval adquire características identitárias nos anos 1970. O autor sugere que nessa década houve uma inflexão histórico-discursiva, que travestirse deixou de ser uma atividade em determinados períodos do ano para ser um sujeito, ou seja, adquire uma característica identitária. Veras (2020) destaca que no tempo das perucas (anterior a 1970) travestir-se era uma prática provisória e clandestina que acontecia "durante as festas temáticas realizadas nos apartamentos de amigos; nos concursos de beleza, que aconteciam em lugares afastados da cidade, como praias e sítios; e, principalmente, nos bailes e blocos carnavalescos, momento em que assumia um caráter semipúblico" (VERAS, 2020, p. 46). O autor aponta que nesse momento era comum a expressão "vou de travesti" (VERAS, 2020, p. 59). As bonecas se apropriavam de "tecnologias de gênero, como maquilagem, peruca, vestido, calcinha, biquíni e sapatos" e performavam ideias de feminilidade nesses eventos (VERAS, 2020, p. 52). Veras (2020) afirma que com a popularização do acesso a hormônios e silicones (médico ou industrial), a afirmação "vou de travesti" se transformou em "virar travesti". Elias Veras (2020) chama esse novo momento de tempo dos hormônios, o qual possibilitou a emergência do sujeito travesti, enquanto identidade. Veras indica que "essa nova personagem fazia uso de outras tecnologias científico-corporais, como hormônios (comprimidos e/ou ampolas injetáveis) e silicone (médico e/ou industrial), para feminilizar o corpo e construir uma aparência feminina" (2020, p. 70). Na atualidade, travesti é uma identidade feminina e, como destaca Amara Moira (2017), não podemos nos apoiar apenas na autoidentificação, porque mesmo dentro da comunidade travesti, se fomos questionar o que elas são, as respostas serão multifacetadas, variando entre as concepções de masculino, feminino ou uma identidade travesti.

Nos anos 60 existiam defensores da necessidade de parodiar as expectativas de gênero proposta pela heteronorma e, em contrapartida, outros sujeitos defendiam a desvinculação dos papéis sociais atribuídos ao homem-mulher "verdadeiro". Nesse contexto de transformações, questionamentos voltados para a igualdade na relação afetiva-sexual foram colocados sob as identidades baseadas nas práticas sexuais e nas noções rígidas de gênero. De tais discussões 
emerge o termo entendido para homens que se relacionam com homens e entendida para mulheres que se relacionavam com mulheres. Esse termo era utilizado por pessoas que não se apoiavam na rigidez das identidades focadas em papéis sexuais e pessoas que achavam a expressão homossexualismo algo formal demais (COSTA, 2010). Os defensores do termo entendido provocaram um rebuliço tanto dentro da rede $O S n o b$ quanto na sociedade brasileira, por promoverem novas leituras acerca da sexualidade já que não se apoiavam dentro da divisão binária de gênero. De forma mais tímida o termo gay adentrou o vocabulário brasileiro após contato de homossexuais brasileiros com estadunidenses e europeus. Com as mesmas premissas do termo entendido, o gay era utilizado para falar das homossexualidades de forma generalizada. Houve em alguns boletins e jornais o abrasileiramento do termo, sendo transcrito na forma de guei.

\section{IDENTIDADES E PRÁTICAS NA TURMA COLATINENSE}

Dado o preâmbulo acerca das identidades que aparecem na coluna Colatina em Hi-Fi e algumas outras em contexto externo, vamos agora a uma análise da aplicação dessas noções dentro do texto de Babette. A modo de contextualização, Rogério da Costa aponta que dentro da rede social $O$ Snob “em 1963, 49\% dos 173 participantes eram relatados como 'bichas' (ou 'bonecas'), e 32\% como 'bofes'. Dos 374 [participantes] de 1964, 55\% foram identificados como 'bichas', e 26\% como 'bofes"” (2010, p. 34). Costa assinala que em 1965 os entendidos entram no jornal, provocando diversos debates acerca das noções de sexualidade e gênero. Nesse momento, inicia-se um conflito entre bichas e entendidos nas páginas do periódico. No grupo dos defensores do termo entendido, o colunista Gato Preto passa a encabeçar o movimento em 1967 (COSTA, 2010). Entendemos que Babette apoiava o uso dos termos bicha e bofe, mas ainda assim, em suas entrevistas promoveu perguntas sobre as noções de entendido e homossexualismo. A coluna Colatina em Hi-Fi entrou n'O Snob junto com outras colunas regionais ${ }^{12}$ em 1965.

\footnotetext{
${ }^{12}$ Rogério da Costa assenta as seguintes cidades e colunistas: "Manaus (AM): Laura Bell. Salvador (BA): Paulette Godiva; Colatina (ES): Babette; Estância (SE): Aloá; Niterói (RJ): Pantera; Campos (RJ): Liz França; Juiz de Fora
} 


\section{Revista \\ Debates Insubmissos}

O termo boneca que aparece cerca de 177 vezes na coluna de Babette ${ }^{13}$ vem sempre precedido de um artigo feminino (a/as/uma/amas) e sucedido do nome de alguma bicha da rede conhecidos em Colatina. Em consonância com a prática do jornal, cada pessoa da turma ${ }^{14}$ de Bebette recebia o pronome de acordo com sua expressão de gênero ou prática sexual. Para Babette, as bonecas eram as que desempenhavam o papel "passivo" no ato sexual e/ou performavam feminilidades. Entretanto, como aponta Rogério da Costa, isso não representa que todas categorizadas como bonecas desempenhavam posição sexual exclusivamente passiva (penetrado) ou performavam feminilidades. O único caso que a palavra boneca foi precedido de artigo masculino e escrito no masculino (boneco) foi na edição de junho de 1966 em que anunciava o show do "boneco" Wanderley Cardoso no aniversário da Princesinha do Norte, que ocorreria no dia 22 de agosto daquele ano $^{15}$. Segundo a coluna, o cantor Wanderley Cardoso $^{16}$ esteve em Colatina em agosto de 1966 e julho de 1967, ambas as vezes para as festividades de aniversário da cidade. Ao empregar o termo "boneco", Babette não insinuava sobre a sexualidade de Wanderley, mas apontava para o fato de que ele era considerado um símbolo sexual de masculinidade para as bonecas colatinenses.

A modo de facilitar a matemática, dividimos as pessoas da turma colatinense entre bofes e bonecas: nos três anos registrados por Babette, pelo menos 31 bonecas (incluindo Babette) faziam parte da turma colatinense, sendo que 21 residiram em Colatina entre 1965 e 1968. Destas, 03 mudaram-se para a cidade de Vitoria, 01 para São Paulo e 01 para Rio de Janeiro. Das outras 10 bonecas restantes, 03 visitaram Colatina e 07 tiveram contato com as bonecas

(MG): Zezé; São Paulo (SP): Ada Portugal; S. Fidelis (RJ): Tainá; S. Luiz Gonzaga (RS): Gigi Bryant; Barbacena (MG): Irmã; Nova York (EUA): Nora Kovak” (2010, p. 43).

${ }^{13}$ Nas edições de 30/05/1967 e s/d/01/1968, a segunda página da coluna não se encontrava nos acervos do AEL.

${ }^{14}$ As turmas (ou grupos) dentro da rede se dividiam de acordo com a localidade e afinidade. Nesse caso, a "turma colatinense" compreendia todas os bofes, bonecas, travestis, homossexuais, entendidos entre outros, que tinham contato direto com Babette, sendo assim, não se restringia apenas aos moradores de Colatina.

${ }^{15}$ Oficialmente Colatina foi elevada à categoria de cidade em 1921. Em 1966, comorava 50 anos da Revolta de Xandoca. Ver: BOU-HABIB FILHO, Namy Chequer. A Revolta de Xandoca: desafio à oligarquia Monteiro no Espírito Santo. 2007. 109 f. Dissertação (Mestrado em História) - Programa de Pós-graduação em História Social das Relações Políticas, Universidade Federal do Espírito Santo, Vitória, 2007.

${ }^{16}$ Biografia de Wanderley Cardoso. Letras, Disponível em: $<$ https://www.letras.com.br/wanderleycardoso/biografia> . Acesso em: 20 jun. 2020. 
colatinenses no carnaval de Vitória em 1966 e 1967. Quanto aos bofes, 08 foram os nomes citados por Babette, sendo 04 residentes em Colatina, 01 em Vitória, 01 em São Paulo. Os outros 02 visitaram Colatina e não foi especificado de onde vieram. Ou seja, dentro da turma colatinense temos cerca de 39 pessoas entre bonecas e bofes, sendo 24 moradores de Colatina. Nesses dados foram ignoradas pessoas não nomeadas como: "Dono de um fabuloso parque de diversão" 17 e a "boneca que marca seus encontros na enorme ponte de nossa cidade"18, entre outros. A diferença do número de bonecas e bofes, pode ser elucidada pelo fato de que o $O$ Snob era majoritariamente escrito por bonecas, logo, privilegiava as fofocas sobre as badalações, vidas sociais, amorosas e sexuais das bonecas. Normalmente as fofocas feitas por Babette eram elogiosas, sendo exceções os mexericos depreciativos. Babette privilegiava fuxicos sobre as bonecas mais próxima a ela como: Sofia, Jaqueline (Jakie), Maísa e Débora. Destas, Bebette destaca que Sofia, Jaqueline e Débora formavam um trio inseparável ${ }^{19}$. Em meados de 1966, novas bonecas aparecem frequentemente nas fofocas, sendo elas Uca, Gilda e Tarina. No ano seguinte, Gygy e Renata entram para o grupo das bonecas mais comentadas. Residente em São Paulo, mas com visitas frequentes a Colatina, Morgana prima de Babette, também apareceu regularmente nas fofocas colatinense.

A coluna levantou poucos questionamentos acerca das sexualidades, entretanto nos relatos foi possível identificar práticas sexuais e expressões de gênero que não se enquadravam na díade boneca-bofe. Babette afirma que Debora (Colatina) e Morgana (São Paulo) fizeram teste para travesti no espetáculo Le Girls, que circulava nos clubes de São Paulo. Babette se questiona: "Será que teremos um travesti colatinense?"20. O Le Girls foi um espetáculo de travestis que passou por diversos teatros nos estados brasileiros entre 1950 e 1980, além de se apresentar em países latino-americanos, africanos e europeus (VERAS, 2020). Na coluna,

\footnotetext{
${ }^{17}$ BABETTE. Colatina em Hi-Fi. O Snob, Rio de Janeiro, p. s/n, 03 dez. 1966. Acervo: TURMA OK. Arquivo Edgard Leuenroth/Universidade Estadual de Campinas.

${ }^{18}$ BABETTE. Colatina em Hi-Fi. O Snob, Rio de Janeiro, p. 15-16, 25 dez. 1965. Acervo: TURMA OK. Arquivo Edgard Leuenroth/Universidade Estadual de Campinas.

${ }^{19}$ BABETTE. Colatina em Hi-Fi. O Snob, Rio de Janeiro, p. s/n, 31 dez. 1966. Acervo: TURMA OK. Arquivo Edgard Leuenroth/Universidade Estadual de Campinas.

${ }^{20}$ BABETTE. Colatina em Hi-Fi. O Snob, Rio de Janeiro, p. 15-16, 25 dez. 1965. Acervo: TURMA OK. Arquivo Edgard Leuenroth/Universidade Estadual de Campinas.
} 


\section{Revista \\ Debates Insubmissos}

travesti aparecia predominantemente como travestismo (ir "de travesti") e a vontade de Débora de participar do espetáculo é resultado da emergência público-mediática do sujeito travesti. Não há relatos de Babette acerca do travestismo em outros momentos que não seja o carnaval, em específico os de Vitória. Babette destaca as expressões de gênero no decorrer do ano a partir das vestimentas, como calças patas-de-elefante, roupas da estação ou "estilo americanizado". Para Débora, e algumas outras da rede, a única possibilidade de sair de travesti era no carnaval. Débora preparava suas roupas com antecedência e se destacou com seus vestidos nos carnavais de 1966 e 1967 em Vitória, e fazia questão que todos a notassem ${ }^{21}$. Ao comentar o carnaval de 1966, Babette destaca que "Débora estava mais bonita de todas e foi a mais comentada" 22 . No carnaval de 1967, Babette afirma que "Débora [...] concorreu ao prêmio originalidade, conseguindo com muito êxito o primeiríssimo lugar com a sua fantasia, confeccionada por ela mesma, denominada: Traje Op-Art" ${ }^{\prime 23}$. Como destaca Elias Veras (2020), o carnaval funcionava como uma heterotopia de gênero, proporcionando liberdade de manifestação das sexualidades e expressões de gênero.

Nas fofocas de Babette, em geral, Débora estava ligada à moda e vestimentas. Antes de se mudar para Vitória, Débora concede entrevista a Babette, que questiona: "Querida, o que diz também do $2^{\circ}$ sexo?”, Débora responde “A mulher? Criaturas criadas por Deus, futuras mães, titias, prostitutas e etc. Cada..."24. A página seguinte da coluna não estava disponível no acervo do Arquivo Edgard Laureouth. Esse é o único momento dentro da coluna em que Babette propõe uma reflexão sobre a ideia de mulher para as bonecas. As outras menções entram no texto enquanto pronome. Com exceção da paulista Morgana, as únicas residentes na Princesinha do Norte que se travestiam no carnaval eram Débora, Sofia e Jaqueline. No que tange a Sofia e Jaqueline, não há relatos de que tiveram uma experiência travesti em outros

\footnotetext{
${ }^{21}$ BABETTE. Colatina em Hi-Fi. O Snob, Rio de Janeiro, p. 10, 28 fev. 1967. Acervo: TURMA OK. Arquivo Edgard Leuenroth/Universidade Estadual de Campinas.

${ }^{22}$ BABETTE. Colatina em Hi-Fi. $O$ Snob, Rio de Janeiro, p. s/n, 03 mar. 1966. Acervo: TURMA OK. Arquivo Edgard Leuenroth/Universidade Estadual de Campinas.

${ }^{23}$ BABETTE. Colatina em Hi-Fi. O Snob, Rio de Janeiro, p. 10, 28 fev. 1967. Acervo: TURMA OK. Arquivo Edgard Leuenroth/Universidade Estadual de Campinas.

${ }^{24}$ BABETTE. Colatina em Hi-Fi. O Snob, Rio de Janeiro, p. 5-6, 30 nov. 1965. Acervo: TURMA OK. Arquivo Edgard Leuenroth/Universidade Estadual de Campinas.
} 


\section{Revista \\ Debates Insubmissos}

momentos e espaços, enquanto Débora, segundo Babette, tentou entrar para o grupo Les Girls. Débora se mudou para Vitória, capital do Espírito Santo, em maio de 1967 para "fins de trabalho" 25 . Os relatos acerca de Débora dão a entender que existia a possibilidade de ela vivenciar uma experiência travesti/transgênero. Nos últimos comentários, Babette afirma que Débora iniciou um namoro com a boneca Adalta, que conheceu no carnaval de Vitória, em fevereiro de 1967. Apesar do discurso da rede $O$ Snob pregar uma incoerência no relacionamento entre duas bonecas, defendendo o par boneca e bofe $e^{26}$, o relacionamento entre Adalta e Débora não foi visto como problemático por Babette. Os relacionamentos de Débora com bofes e bonecas mostram como a noção de boneca como feminina e passiva não condiz com a experiência real de sexualidade.

O termo entendido aparece nos escritos de Babette em três formas: em novembro de 1965 como um complemento de bofe (bofes "entendidos") 27 ; em março de 1966 de forma mais ampla englobando toda sociedade "bichal"28; e em fevereiro de 1967 no qual é colocado como um sinônimo de "simpatizante" ao falar do gerente do Palace Hotel em Vitória e sua esposa 29 . Nesse último caso, Rogério da Costa (2010) aponta para a polissemia da expressão entendido dentro da rede, e reitera que

"entendido" designava todas as pessoas que "entendesse", no sentido, de aceitar,
valorizar e compartilhar o modo de vida das "bichas". Dessa maneira, um
heterossexual pode ser classificado como "entendido", desde que compartilhe dessa
"sociedade", o que se assemelha ao que hoje chamamos de "simpatizantes"; adianto,
porém, que os termos comportam diferenças importantes (COSTA, 2010, p. 36).

A diferença apontada por Rogério da Costa está nas aplicações da divisão identitária hétero-homo, pois enquanto o entendido heterossexual comunga com a visão de mundo da

\footnotetext{
${ }^{25}$ BABETTE. Colatina em Hi-Fi. O Snob, Rio de Janeiro, p. s/n, 30 abr. 1967. Acervo: TURMA OK. Arquivo Edgard Leuenroth/Universidade Estadual de Campinas.

${ }^{26}$ Rogério Costa apresenta esse debate com uma fala de Agildo Guimaraes no qual coloca "Na época não tinham duas bichas... Podiam até ter relações, mas nunca foi..." (2010, p. 70).

${ }^{27}$ BABETTE. Colatina em Hi-Fi. O Snob, Rio de Janeiro, p. 5-6, 30 nov. 1965. Acervo: TURMA OK. Arquivo Edgard Leuenroth/Universidade Estadual de Campinas.

${ }^{28}$ BABETTE. Colatina em Hi-Fi. O Snob, Rio de Janeiro, p. s/n, 03 mar. 1966. Acervo: TURMA OK. Arquivo Edgard Leuenroth/Universidade Estadual de Campinas.

${ }^{29}$ BABETTE. Colatina em Hi-Fi. O Snob, Rio de Janeiro, p. 10, 28 fev. 1967. Acervo: TURMA OK. Arquivo Edgard Leuenroth/Universidade Estadual de Campinas.
} 
"sociedade bichal" e "participa" do mercado sexual, para os "simpatizantes" os homossexuais "continuam sendo o "outro"” (2010, p. 62). Em sua forma ampla o termo podia ser aplicado na variação feminina (entendida) para nominar lésbicas, ou também para designar uma característica de um espaço, destacando que determinado local era aberto para a presença de homossexuais. Em aplicação similar à expressão entendido, o termo gay é utilizado por Babette em duas ocasiões: a primeira como uma denominação de um espaço simbólico (meio gay) ${ }^{30}$, e a segunda como uma identidade de grupo (classe gay colatinense) ${ }^{31}$. As duas situações acontecem no segundo semestre de 1967 e são fruto do contato brasileiro com as identidades sexuais estadunidenses e européias. Tanto fora quanto dentro da rede, a expressão gay foi utilizada de forma tímida no Brasil dos anos 1960.

Por fim, o termo homossexualismo ocorre na coluna apenas uma vez, na entrevista de Maísa concedida a Babette em setembro de 1967. Babette questiona: "Antes de tudo o que acha você do homossexualismo?" e Maísa responde: “Ao meu ver o homossexualismo está evoluindo dia a dia, dando-nos a oportunidade de sermos livres" ${ }^{32}$. Na pergunta e na resposta, homossexualismo aparece de forma ampla, nos mesmos moldes de gay e entendido, e Maísa acentua um caráter evolutivo, destacando que com os passar dos tempos as experiências homossexuais estão ganhando mais liberdade. Apesar do regime militar evocar um discurso conservador acerca das sexualidades desviante, a impressão de Maísa fazia parte de um imaginário da "sociedade bichal" da época, pois os anos 1960 se destacaram pela revolução sexual e o aparecimento de locais de sociabilidades de pessoas que tinham interesse em pessoas do mesmo sexo. Com isso entramos no próximo tópico em que abordamos os pontos de sociabilidades em Colatina.

\section{SOCIABILIDADES}

\footnotetext{
${ }^{30}$ BABETTE. Colatina em Hi-Fi. O Snob, Rio de Janeiro, p. 19, 31 ago. 1967. Acervo: TURMA OK. Arquivo Edgard Leuenroth/Universidade Estadual de Campinas.

${ }^{31}$ BABETTE. Colatina em Hi-Fi. O Snob, Rio de Janeiro, p. s/n, 31 out. 1967. Acervo: TURMA OK. Arquivo Edgard Leuenroth/Universidade Estadual de Campinas.

${ }^{32}$ BABETTE. Colatina em Hi-Fi. O Snob, Rio de Janeiro, p. 11, 30 set. 1967. Acervo: TURMA OK. Arquivo Edgard Leuenroth/Universidade Estadual de Campinas.
} 


\section{Revista \\ Debates Insubmissos}

O município de Colatina passava por processo de profundas mudanças socioeconômicas durante os anos 1960. A erradicação dos cafezais, iniciada na década anterior, provocou migrações de áreas rurais para urbanas que ocasionou um crescimento do núcleo urbano da cidade. Os arredores do centro de Colatina, tanto na parte ao sul do Rio Doce quanto ao norte, foram ocupados por parcela da população oriunda do meio rural o que resultou na ampliação das atividades comerciais e industriais e na oferta de empregos, promovendo assim uma modernização social e econômica da cidade. Por outro lado, devido ao seu vasto território, o município se fragmentava dando origem a cidades como Pancas e São Gabriel da Palha, ambas fundadas em 1963 (ALBANI 2012). Essa conjuntura surge nas narrativas de Babette, como vamos destacar a seguir.

São pelo menos 09 locais que Babette destaca como possíveis de se encontrar bonecas e bofes, sendo 01 restaurante, 01 bar, 01 clube, 01 cinema, 01 avenida, 01 ponte, 01 ladeira, 01 bairro, 01 rua, destes apenas a rua é considerada um local entendido de frequência da turma colatinense. Já no primeiro texto de Babette para o jornal foi relatado sobre a rua Pancas no bairro São Silvano, conhecida pelos bofes da cidade como Rua das Mulheres Perdidas. Segundo Babette, o bairro São Silvano era "um dos bairros mais movimentados de nossa cidade" 33 pois residem nele as bonecas mais "badaladas" de Colatina. A Rua das Mulheres Perdidas, que se localizava na área limítrofe ao norte do bairro, era ponto de encontro e de pegação das bonecas e dos bofes colatinenses. Durante o ano de 1965, a rua não tinha iluminação pública, o que proporcionava às bonecas e bofes cantos escuros para pegações. De acordo com Babette, de vez em quando aparecia "algum bofe com a sua malinha ligeiramente endurecida por entre as calças" ${ }^{34}$. Os escritos deixam a entender que a Rua Pancas era o local frequentado por todas bonecas e bofes independente de classe social. Ainda em janeiro de 1965, Babette comenta que o prefeito da cidade mandou iluminar a rua gerando revolta por parte das

\footnotetext{
${ }^{33}$ BABETTE. Colatina em Hi-Fi. O Snob, Rio de Janeiro, p. s/n, 31 set. 1966. Acervo: TURMA OK. Arquivo Edgard Leuenroth/Universidade Estadual de Campinas.

${ }^{34}$ BABETTE. Colatina em Hi-Fi. O Snob, Rio de Janeiro, p. 5-6, 30 nov. 1965. Acervo: TURMA OK. Arquivo Edgard Leuenroth/Universidade Estadual de Campinas.
} 


\section{Revista \\ Debates Insubmissos}

bonecas $^{35}$. No decorrer do ano, a Rua das Mulheres Perdidas continuou a ser frequentada por bonecas e bofes colatinenses, porém, em meados de junho de 1966, ela começa a ser abandonada pelas "queridíssimas bonecas e gostosíssimos bofes"36.

As bonecas de classe média-alta tinham condições de frequentar bares e clubes da cidade. Inaugurado em 1962, o restaurante Drink, que se localizava às margens do Rio Doce, ao lado da ponte Florentino Avidos, com vista para o Centro da cidade do outro lado do rio, foi ponto de encontro de bonecas e bofes. Em janeiro de 1965, Babette relata que algumas bonecas acompanhadas de marinheiros foram ao restaurante Drink. Em novembro do mesmo ano, ela relata que o restaurante estava ficando famoso e frequentado assiduamente por algumas bonecas $^{37}$. Pelo local e pela gastronomia servida no Drink, somente bonecas de classe médiaalta tinham condições financeiras de frequentar esse espaço, sendo Maísa a única citada. Em alguns momentos, os escritos deixam a entender que Maísa, Jaqueline, Débora e Sofia são bonecas com boas condições financeiras. Outro ponto que foi frequentado por essas bonecas era o Iate Clube, que se localizava no Centro da cidade, ao sul do Rio Doce, próximo à ponte. O Iate clube foi inaugurado em dezembro de 1965 e foi por anos o local das principais festas de debutantes, bailes de carnaval e halloween, casamentos, eventos políticos e sociais. $\mathrm{Na}$ Figura 01 podemos ver o Iate Clube no canto superior esquerdo destacado por sua arquitetura modernista com o teto em formato de seis conchas. Em dezembro de 1965, Babette escreveu que ocorreu no Iate Clube o Baile das Bruxas, em que todos estavam mascarados, o que proporcionou que a "elite bichal" 38 fosse toda fantasiada.

\footnotetext{
${ }^{35}$ BABETTE. Colatina em Hi-Fi. O Snob, Rio de Janeiro, p. 19-20, 31 jan. 1965. Acervo: TURMA OK. Arquivo Edgard Leuenroth/Universidade Estadual de Campinas.

${ }^{36}$ BABETTE. Colatina em Hi-Fi. O Snob, Rio de Janeiro, p. s/n, s/d jun. 1966. Acervo: TURMA OK. Arquivo Edgard Leuenroth/Universidade Estadual de Campinas.

${ }^{37}$ BABETTE. Colatina em Hi-Fi. $O$ Snob, Rio de Janeiro, p. 5-6, 30 nov. 1965. Acervo: TURMA OK. Arquivo Edgard Leuenroth/Universidade Estadual de Campinas.

${ }^{38}$ BABETTE. Colatina em Hi-Fi. O Snob, Rio de Janeiro, p. 15-16, 25 dez. 1965. Acervo: TURMA OK. Arquivo Edgard Leuenroth/Universidade Estadual de Campinas.
} 


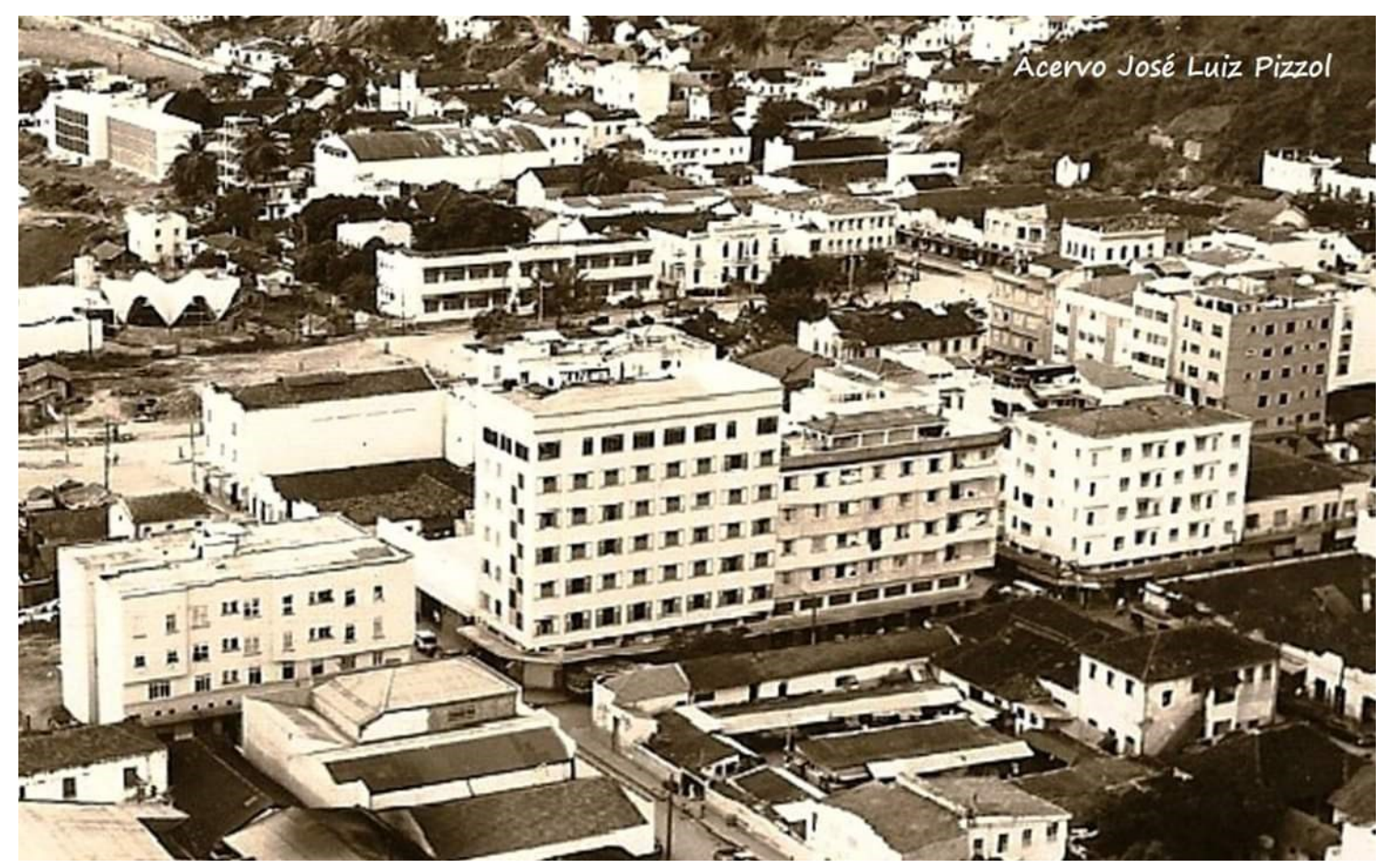

Figura 1: Centro de Colatina ao sul do Rio Doce em 1962. O Iate Clube está localizado no canto superior esquerdo em formato de oito conchas ${ }^{39}$.

Um terceiro local frequentado pelas bonecas colatinenses era o Big Bar, localizado em um hotel não especificado. Em abril de 1967, o bofe Mário e boneca Maísa foram destacados como frequentadores assíduos do estabelecimento ${ }^{40}$. Em maio, antes de se mudar para Vitória, a boneca Débora comemorou seu aniversário no Big Bar. Em novembro do mesmo ano, Babette fuxicou que uma boneca estava "fazendo fabulosas pegações na discrição do Big Bar". Diferente da Rua das Mulheres Perdidas, esses três espaços (restaurante, clube e bar) não eram frequentados exclusivamente por bofes e bonecas. A "comunidade bichal" de Colatina que tinha condições de arcar com entrada e consumo, apropriam-se desses espaços para seus encontros amorosos, festas e badalações, ou em busca de outros entendidos, como no caso do clube e do bar.

39 Obra da Praça Municipal de Colatina nos anos 1960. Acervo: José Luiz Pizzol. Disponível em: $<$ https://colatinaemacao.com.br/2019/09/17/predios-da-rua-independencia-em-colatina-foto-de-1962/>. Acesso em: 20 mai 2020.

${ }^{40}$ BABETTE. Colatina em Hi-Fi. O Snob, Rio de Janeiro, p. s/n, 30 abr. 1967. Acervo: TURMA OK. Arquivo Edgard Leuenroth/Universidade Estadual de Campinas. 


\section{Revista \\ Debates Insubmissos}

Quem não tinha condições econômicas de frequentar esses espaços ou de vivenciar sua sexualidade em casa ou num motel/hotel, buscava espaços públicos nos arredores da cidade. Babette cita duas situações desse tipo. A primeira, já comentada anteriormente, de uma boneca que marca seus encontros na ponte Florentino Avidos. Babette alerta para a boneca tomar cuidado pois o local é escuro e o rio fundo ${ }^{41}$. Um segundo local citado é a ladeira que uma boneca levava seus bofes para "acontecer horrivelmente" 42 . Esses espaços à margem utilizados por bonecas e bofes para fins sexuais evidenciam a desigualdade na vivência da sexualidade entre os membros da turma colatinense. Babette mostra preocupação com o bem estar das bonecas e bofes que fazem pegação na ponte. Em uma cidade interiorana onde há ausência de locais e espaços para a sociabilidade de homossexuais, a desigualdade de classe torna-se um fator que diferencia as formas de vivência da sexualidade. Quando a Rua das Mulheres Perdidas era o principal ponto de encontro de bonecas e bofes colatinenses, existia um certo tipo de democratização das pegações dado que era frequentada por bichas e bofes de diversas camadas sociais. Após o abandono desse ponto cada um teve de procurar outros locais dentro e na periferia da cidade para a sociabilidade.

A racialidade pode ser outro fator que diferenciou as vivências da sexualidade em Colatina. A única boneca racializada por Babette foi Vera Regina "que é da cor do carvão"43. Durante todo tempo de circulação da coluna, as bonecas foram diferenciadas entre louras e morenas, altas e baixas, magras e gordas, sendo esse comentário a única manifestação do tipo acerca da cor de pele das bonecas. Em outro momento, porém, Babette utiliza o termo "mulata" para elogiar a "elegantérrima Miss Guanabara (Vera Couta)"44. A palavra mulata era muito comum no linguajar popular brasileiro, entretanto, esta possui uma origem racista e atualmente o movimento negro reivindica o fim da utilização desse termo. Nos registros do Colatina em

\footnotetext{
${ }^{41}$ BABETTE. Colatina em Hi-Fi. O Snob, Rio de Janeiro, p. 15-16, 25 dez. 1965. Acervo: TURMA OK. Arquivo Edgard Leuenroth/Universidade Estadual de Campinas.

${ }^{42}$ BABETTE. Colatina em Hi-Fi. O Snob, Rio de Janeiro, p. s/n, 31 mai. 1967. Acervo: TURMA OK. Arquivo Edgard Leuenroth/Universidade Estadual de Campinas.

${ }^{43}$ BABETTE. Colatina em Hi-Fi. O Snob, Rio de Janeiro, p. 15-16, 25 dez. 1965. Acervo: TURMA OK. Arquivo Edgard Leuenroth/Universidade Estadual de Campinas.

${ }^{44}$ BABETTE. Colatina em Hi-Fi. O Snob, Rio de Janeiro, capa, 08 jul. 1967. Acervo: TURMA OK. Arquivo Edgard Leuenroth/Universidade Estadual de Campinas.
} 


\section{Revista \\ Debates Insubmissos}

$H i-F i$ não fica evidente até que ponto o racismo brasileiro interferiu nas sociabilidades das bonecas e bofes colatinenses. Destacar a coloração preta da pele de Vera Regina em um comentário não significa que todas as outras bonecas da turma eram brancas. A própria característica "morena" muitas vezes é utilizada para especificar pessoas negras, principalmente quando partida de uma pessoa branca com receio de falar negra ou preta. Entretanto, com esses dois únicos comentários não é possível tecermos hipóteses acerca de experiências étnico-raciais da turma colatinense. Muito embora seja possível inferir a partir do não dito e do silêncio, até porque o lugar de classe, no Brasil, vem sempre acompanhado de lugar de cor. E podemos imaginar o grande número de bonecas e bofes pobres no armário, que jamais seriam vistos ou contemplados pela coluna.

Algumas intrigas aconteceram na cidade, sendo a maioria resultado de fofocas. A primeira é protagonizada por Sofia (Colatina) e Georgia (Vitória), na qual o "maridinho [de Sofia] não deixa Georgia em paz" ${ }^{45}$. A situação resultou em briga entre as duas bonecas. Ao relembrar o fato, dois anos depois, Babette comenta de forma contraditória:

Bom, mas aí a nossa Sofia teve toda razão, além de vir a nossa cidade, deixando tantos capixabas bárbaros lá em Vitória e querer pegar logo um Colatinense. E ainda por cima casado. Essa não! Porque ela não escolheu os solteiríssimos que estavam dando sopa as pampas? ${ }^{46}$.

Mesmo defendendo a amiga mais próxima, Babette não deixou de tecer elogios a Georgia no decorrer da existência da coluna. Além de Débora e Adilda, não existiu relato de outras bonecas que se relacionavam entre si, o que limitava a quantidade de relacionamento entre a turma colatinense, dado que era conflituoso no pensamento social da rede o relacionamento entre duas bonecas. Outra intriga, também protagonizada por Sofia, ocorreu com sua amiga Débora em uma noite na avenida Getúlio Vargas, principal avenida de Colatina na época. Pouco antes de Débora ir morar em Vitória, as duas amigas se desentenderam. Babette

\footnotetext{
${ }^{45}$ BABETTE. Colatina em Hi-Fi. $O$ Snob, Rio de Janeiro, p. 5-6, 30 nov. 1965. Acervo: TURMA OK. Arquivo Edgard Leuenroth/Universidade Estadual de Campinas.

${ }^{46}$ BABETTE. Colatina em Hi-Fi. O Snob, Rio de Janeiro, p. s/n, 30 abr. 1967. Acervo: TURMA OK. Arquivo Edgard Leuenroth/Universidade Estadual de Campinas.
} 
afirma que por Débora ser a mais forte levou a melhor ${ }^{47}$. Esse segundo conflito levou Babette a questionar: "Francamente, porque nós, principalmente nós, bonecas, não conseguimos viver unidas. Afinal de contas somos uma família, precisamos de união, certo?”. Esta foi uma segunda manifestação de Babette, que concebe a "classe bichal" como um grupo que deve permanecer unido. Esse processo de transformação da sexualidade enquanto algo individual em algo coletivo mostra a construção de uma identidade de grupo baseada nas vivências de sexualidades e gênero daquela comunidade. Apesar dessa construção se apresentar visível num cenário nacional das grandes capitais desde os anos 1930, parece que a turma colatinense passava por esse processo durante os anos 1960, dado que Babette começou a relatar a turma colatinense como "sociedade bichal”, “classe gay”, "comunidade", "grupo”, “nós” em meados de 1966.

Por fim, um espaço que passou a ser ocupado pelas bonecas e bofes colatinenses foi a Avenida Getúlio Vargas, na qual durante as noites e madrugadas poderiam buscar por pessoas entendidas. Na mesma avenida, a turma colatinense começou a frequentar o Cine Idolmar que estava "cada vez mais florido, com a presença mágica da classe gay colatinense" ${ }^{2}$. A sala de cinema, inaugurada em 1956, tinha espaço para cerca de mil pessoas, o que proporcionava pegações em sessões mais vazias. O cinema tornou-se outro espaço apropriado por grupos homossexuais para encontrar semelhantes.

\section{MIGRAÇÕES E INTERCÂMBIOS}

Nessa sessão faremos uma análise das migrações registradas por Babette, buscando trazer à torna as trocas culturais que permitiam debates e questionamentos acerca das experiências em cada cidade. James Green (2000) aponta que durante o século XX houve um movimento de migrações para as grandes cidades, de jovens que tomaram consciência de seus desejos e fantasias sexuais. Esses sujeitos se mudavam para cidades como São Paulo e Rio de Janeiro pois a alta densidade demográfica desses centros urbanos proporcionava um certo tipo

\footnotetext{
${ }^{47}$ BABETTE. Colatina em Hi-Fi. O Snob, Rio de Janeiro, p. s/n, 30 abr. 1967. Acervo: TURMA OK. Arquivo Edgard Leuenroth/Universidade Estadual de Campinas.

${ }^{48}$ BABETTE. Colatina em Hi-Fi. O Snob, Rio de Janeiro, p. s/n, 31 out. 1967. Acervo: TURMA OK. Arquivo Edgard Leuenroth/Universidade Estadual de Campinas.
} 
de anonimato. No decorrer dos 1950, com a emergência de boates e bares, locais de encontro de homossexuais masculinos e femininos, esse movimento migratório se intensificou, visto que essas cidades proporcionavam uma fuga dos valores e do controle de cidades interioranas garantindo, ao mesmo tempo, espaços de sociabilização de sujeitos com interesses sexuais comuns. O anonimato era outro ponto de interesse desses sujeitos que as grandes cidades garantiam (garantem). A grande concentração de pessoas em um mesmo espaço proporcionava que os/as entendidos/as pudessem vivenciar suas sexualidades e expressões de gênero de forma menos controlada pelo meio social do que em uma cidade pequena ou média. Esse mesmo movimento migratório, muitas vezes de um estado para o outro, também pode ser visto de pequenas para médias cidades.

Colatina, que fica a cerca de $130 \mathrm{~km}$ da capital Vitória, era a cidade mais populosa do Espírito Santo nos anos 1960. Para os moradores das cidades rurais e interioranas, Colatina era referência no estado em empregabilidade e produção econômica. Algumas das bonecas e dos bofes da turma colatinense não eram naturais de Colatina ou do Espírito Santo. Maísa era nascida em Governador Valadares (MG) e Débora de Afonso Claudio (ES). O que levou a família das bonecas a se mudar para Colatina não é especificado na coluna, mas provavelmente está relacionado à produção de café que levou a cidade a ter um crescimento urbano considerável entre 1940 e 1960. Com a erradicação dos cafezais nos anos 1960, houve dois tipos de migrações: da área rural de Colatina para o centro urbano cidade; e do interior do Estado para a Região Metropolitana da Grande Vitória ${ }^{49}$. Todos os dois movimentos foram marcados pela procura de emprego. Babette relata que em 1965, Lucrécia pensou em se mudar para o Estado da Guanabara (RJ), mas apenas o faz em 1966. Neste ano, Vera Regina se muda para Vitória, seguida de Débora, em 1967, que também se muda para capital por motivos de trabalho. Tarina, que já morou em Colatina, residiu em Vitória durante os três anos da coluna e mudou-se para São Paulo em agosto de 1967. Um mês depois, Ranata se muda para Guanabara. As trocas de residência entre cidades ocorreram majoritariamente de municípios de pequeno e médio porte para as capitais. Em comparação às cidades interioranas, as capitais

\footnotetext{
49 Grande Vitória é o nome dado a região metropolitana do Espírito Santo que concentra os municípios de Cariacica, Fundão, Guarapari, Serra, Viana, Vila Velha e a capital Vitória.
} 


\section{Revista \\ Debates Insubmissos}

proporcionavam maior liberdade cultural, artística e social, para além da empregabilidade. Nesses quesitos, as cidades de São Paulo e Rio de Janeiro eram referência em âmbito nacional.

Numa perspectiva estadual, as capitais representavam o mais próximo da liberdade das grandes cidades. No caso do Espírito Santo, a capital Vitória, principalmente o centro da cidade, era referência de uma vida boêmia e cultural nos anos 1960. O contato que a turma colatinense tinha com a cidade de Vitória durante os carnavais possibilitava comparações, tanto entre Colatina e Vitória quanto entre Vitória e São Paulo/Rio de Janeiro. Babette questiona, após o carnaval de 1966, que Vitória não tem um teatro "apropriado para receber seus travestis" 50 . Os concursos de travestis ocorridos na capital capixaba aconteciam nos arredores do Teatro Carlos Gomes. Nesse momento, ela faz uma comparação com os concursos de travestis que ocorriam nos teatros do Rio de Janeiro, como Teatro João Caetano, Teatro Recreio, Teatro República entre outros (GREEN, 2000).

Durante todo o ano de 1966, Babette cita rumores da possibilidade de ocorrer um baile de travestis no Teatro Carlos Gomes em Vitória ${ }^{51}$. O baile não chega a acontecer, mas houve no "Teatro Municipal de Vitória" 52 um concurso de travestis, no qual Débora ganhou o primeiro lugar no quesito originalidade ${ }^{53}$. Os contatos com as capitais capixaba, carioca e paulista oportunizavam um intercâmbio entre as bonecas e bofes de cidades interioranas com as das cidades grandes. Os contatos mistos proporcionavam que a turma colatinense reivindicasse espaços - como o concurso de travesti no "Teatro Municipal de Vitória" - ao mesmo tempo que promoviam debates internos sobre as conquistas de liberdades que outros "grupos" homossexuais adquiriram em suas cidades. Essas trocas de informações aconteciam

\footnotetext{
${ }^{50}$ BABETTE. Colatina em Hi-Fi. $O$ Snob, Rio de Janeiro, p. s/n, 03 mar. 1966. Acervo: TURMA OK. Arquivo Edgard Leuenroth/Universidade Estadual de Campinas.

${ }^{51}$ BABETTE. Colatina em Hi-Fi. O Snob, Rio de Janeiro, p. s/n, 03 dez. 1966. Acervo: TURMA OK. Arquivo Edgard Leuenroth/Universidade Estadual de Campinas.

52 Babette se refere ao teatro em que aconteceu o concurso de travestis em 1967 como "Teatro Municipal de Vitória", entretanto, não foi identificado a existência de um teatro municipal em Vitória durante os anos 1960. Deixamos entre aspas a modo que essa informação será verificada em jornais locais para compor a dissertação.

${ }^{53}$ BABETTE. Colatina em Hi-Fi. O Snob, Rio de Janeiro, p. 10, 28 fev. 1967. Acervo: TURMA OK. Arquivo Edgard Leuenroth/Universidade Estadual de Campinas.
} 
principalmente nos carnavais. Em 1966, Bebette e Débora levaram exemplares d'O Snob para apresentar a rede às bonecas e bofes da capital capixaba ${ }^{54}$. Esses contatos e diálogos, permitidos a partir dos periódicos domésticos, viabilizava a moldura de uma cultura gay no Brasil, permitindo que tanto as grandes cidades quanto as pequenas e médias consumissem informações e valores acerca da sua condição.

\section{CONSIDERAÇÕES FINAIS}

Deixamos de fora dessa abordagem as questões acerca das violências sofridas por bonecas e bofes colatinenses a modo de privilegiar uma análise voltada para as identidades, modos de sociabilidade e os contatos com "iguais" de outras regiões. Sabemos que o próprio processo de estigmatização desses sujeitos perante a sociedade heterocentrada tem participação na produção das identidades e nas formas de sociabilidade. Entretanto, esse assunto merecerá ser tratado com maior profundidade em outros trabalhos. $\mathrm{O}$ que podemos perceber, ao resgatar as sociabilidades de bonecas e bofes de Colatina nos anos 1960, é que existia um diálogo constante com "grupos" de outros municípios e estados. O próprio periódico $O$ Snob servia como uma forma de interlocução e compartilhamento dessas vivências.

Pensar a experiência de uma cidade com economia voltada para a agricultura e agropecuária, e passando por um processo de desenvolvimento urbano nos permite verificar como a transformação do espaço urbano interfere nas formas de sociabilidade. A turma colatinense, por meio d'O Snob, tinha acesso privilegiado aos debates nacionais acerca da sexualidade, e isso possibilitava que ela reproduzisse e criasse formas próprias de homossociabilidades no contexto urbano de Colatina. Por fim, deixamos em aberto um comentário de Babette que pode despertar interesse para futuras pesquisas:

Existe um certo colunista colatinense que escreve as suas colunas para jornal de Colatina. Deu agora na telha do bofético incluir o que as bonecas fazem na cidade.

\footnotetext{
${ }^{54}$ BABETTE. Colatina em Hi-Fi. O Snob, Rio de Janeiro, p. s/n, 03 mar. 1966. Acervo: TURMA OK. Arquivo Edgard Leuenroth/Universidade Estadual de Campinas.
} 
Devo dizer que isto para nós é apenas badalação. Ainda agradeço o ilustre confrade, das nossas fofocas serem expostas ao público na Rota Social. Imaginem! $!^{55}$

\section{REFERÊNCIAS}

ALBANI, Vivian. Trajetória do crescimento da cidade de Colatina. 2012. 166 f. Tese (Doutorado em Arquitetura e Urbanismo) - Programa de Pós-Graduação em Arquitetura e Urbanismo (PPGAU), Universidade Federal do Espírito Santo, Vitória, 2012.

BUTLER, Judith. Problemas de gênero: feminismo e subversão da identidade. Rio de Janeiro: Civilização Brasileira, 2003.

COSTA, Rogério da Silva Martins. Sociabilidade homoerótica masculina no Rio de Janeiro na década de 1960: Relatos do jornal O Snob. 2010. 129 f. Dissertação (Mestrado em História, Política e Bens Culturais) - Programa de Pós-Graduação em História, Política e Bens Culturais, Fundação Getúlio Vargas, Rio de Janeiro, 2010.

FOUCAULT, Michel. História da sexualidade I: a vontade de saber. Rio de janeiro: Graal, 1988.

GREEN, James. Além do Carnaval: a homossexualidade masculina no Brasil do século XX. São Paulo: UNESP, 2000.

MACRAE, Edward. A construção da igualdade: identidade sexual e política no Brasil da "abertura". Campinas: Editora UNICAMP, 1990.

MISKOLCI, Richard. A Teoria Queer e a Sociologia: o desafio de uma analítica da normalização. Sociologias, n. 21, p. 150-182, 2009.

MOIRA, Amara Rodovalho. O cis pelo trans. Estudos Feministas, v. 25, n. 1, p. 365-373, 2017.

NOGUEIRA, Nádia. Invenções de si em histórias de amor: Lota Macedo Soares e Elizabeth Bishop. 2005. 315 f. Tese (Doutorado em História) - Instituto de Filosofia e Ciências Humanas (IFCH), Universidade Estadual de Campinas, 2012.

SILVA, Tomaz Tadeu. A produção social da identidade e da diferença. In: SILVA, Tomaz Tadeu da (Org.). Identidade e diferença: a perspectiva dos estudos culturais. Petrópolis: Vozes, 2005. p. 73-102.

VERAS, Elias Ferreira. Travestis: carne, tinta e papel. Curitiba: Appris, 2020.

WOODWARD, Kathryn. Identidade e diferença: uma introdução teórica e conceitual. In:

\footnotetext{
${ }^{55}$ BABETTE. Colatina em Hi-Fi. $O$ Snob, Rio de Janeiro, p. s/n, s/d jun. 1966. Acervo: TURMA OK. Arquivo Edgard Leuenroth/Universidade Estadual de Campinas.
} 
Revista

Debates Insubmissos

SILVA, Tomaz Tadeu da (Org.). Identidade e diferença: a perspectiva dos estudos culturais. Petrópolis: Vozes, 2005. p. 7-72.

Submetido em: 05/06/2020

Aprovado em: 16/07/2020 